\title{
Circulating Tumor Marker Isolation with the Chemically Stable and Instantly Degradable (CSID) Hydrogel ImmunoSpheres
}

Young Jun Kim, ${ }^{\dagger}$ Young-Ho Cho, ${ }^{*}+\dagger$ Junhong Min, ${ }^{\ddagger}$ Sae-Won Han ${ }^{\S}$

$\dagger$ Cell Bench Research Center, Korea Advanced Institute of Science and Technology (KAIST), 291 Daehak-ro, Yuseong-gu, Daejeon 34141, Republic of Korea

$\$$ School of Integrative Engineering, Chung-Ang University, Heukseok-dong, Dongjak-gu, Seoul 06974, Republic of Korea

${ }^{\S}$ Department of Internal Medicine, Seoul National University Hospital, 101, Daehak-ro, Jongno-gu, Seoul 03080, Republic of Korea

\author{
*Corresponding author \\ Cell Bench Research Center, \\ Korea Advanced Institute of Science and Technology (KAIST), \\ 291 Daehak-ro, Yuseong-gu, Daejeon 34141, Republic of Korea \\ Tel.: +82-42-350-8691 / Fax: +82-42-350-8690 / E-mail: nanosys@kaist.ac.kr
}




\section{Table of Contents}

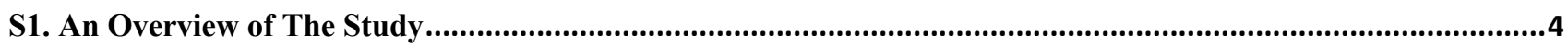

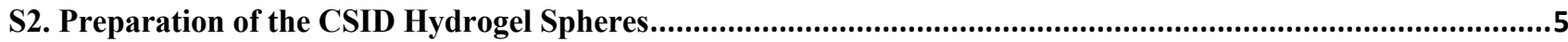

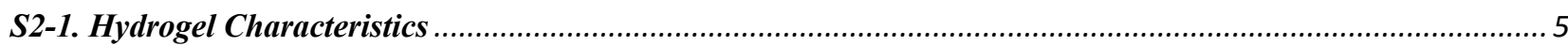

S2-2. Basic Premise for the ImmunoSphere Design: Carrying Capacity............................................................ 6

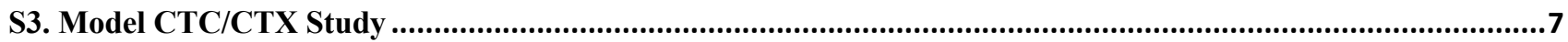

S3-1. Methods: Surface Modification of the CSID Hydrogel Spheres ............................................................ 7

S3-2. Methods: Antibody Immobilization of the CSID Hydrogel Spheres ........................................................... 7

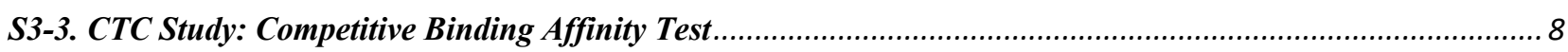

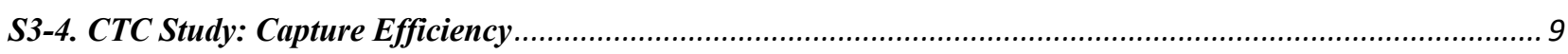

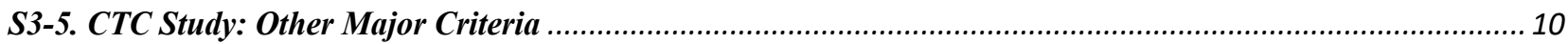

S3-6. CTC Study: The Role of W-CSID ImmunoSpheres in this Study …....................................................... 11

S3-7. CTX Study: Capture Efficiency and Other Major Criteria .................................................................... 12

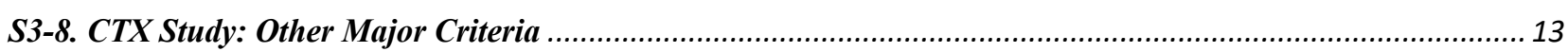

S3-8 CTC/CTX Study: Colorized FE-SEM images of the CSID Hydrogel ImmunoSpheres ................................. 14

S3-9. CTC/CTX Study: FE-SEM images of the CSID ImmunoSpheres after Natural Air Drying......................... 14

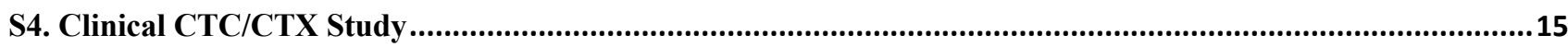

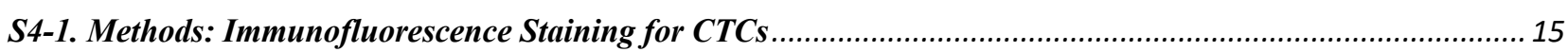

S4-2. Methods: Immunofluorescence Staining for CTXs .......................................................................... 15

S4-3. CTC Study: Immunofluorescence Image of the Isolated CTC ............................................................ 16

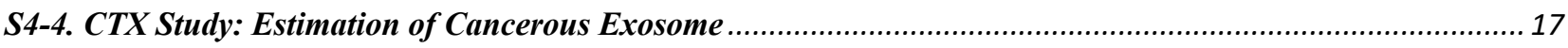

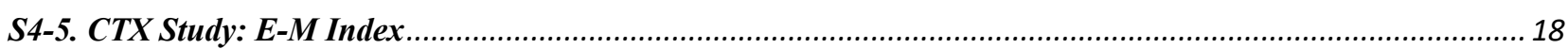

S4-6. CTX Study: Particle Size Distribution (PSD)-based CTX Analysis .............................................................. 19

S4-7. CTC/CTX Study: Patients Information and Result Summary ……........................................................ 20

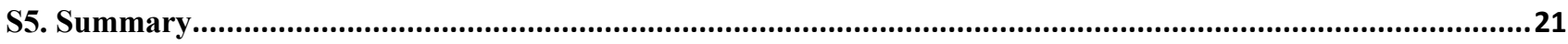

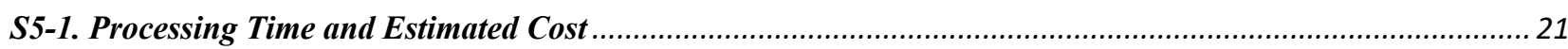

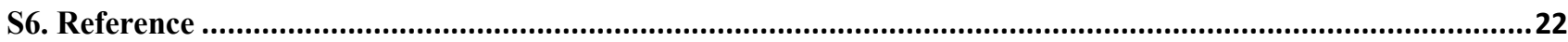


Figures \& Tables

Figure S1. An overview of the experimental procedure for the study .................................................................................. S4

Figure S2. The photographic images of the present CSID hydrogel spheres ................................................................55

Figure S3. Competitive binding affinity test for the C-CSID ImmunoSpheres................................................................... S8

Figure S4. A scheme for potential application focusing on the role of W-CSID ImmunoSpehers ................................. S11

Figure S5. FE-SEM images of the CSID hydrogel ImmunoSpheres after natural air drying ....................................... S14

Figure S6. The representative images of the heterogeneous CTCs isolated by the C-CSID spheres .............................. S16

Figure S7. The estimation of the relevance between the number of the CTCs and E-M index of the CTX.................. S18

Table S1. Comparison of Capture Efficiency with the Well-Established Affinity-based CTC Isolation Methods.......... S9

Table S2. Performance Evaluation with the Major Criteria in CTC Research ........................................................... S10

Table S3. Performance Evaluation with the Major Criteria in CTX Research ................................................................. S13

Table S4. The Particle Size Distribution (PSD) of the Retrieved Samples from the E-CSID ImmunoSpheres ............. S19

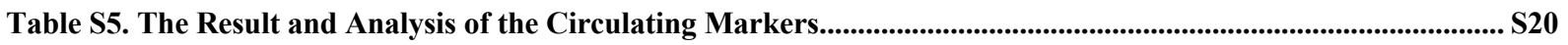

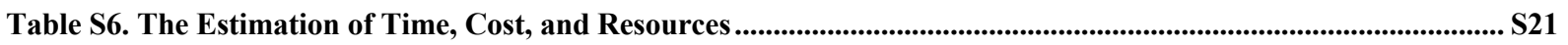




\section{S1. An Overview of The Study}

The present study consists of three parts: (a) the material analysis for the CSID hydrogel spheres, including size(1-1), weight(1-2), shrink-swell ratio (S-S ratio; 1-3), pH-responsive behavior(1-4), chemical stability(1-5), and degradability(1-6); (b) the performance verification of the antibody-immobilized versions of the CSID spheres (C-CSID ImmunoSphere, E-CSID ImmunoSphere, etc.) using model CTC/CTX samples (A1 and B1); (c) proof-of-concept study using cancer patients'samples (PBMC and plasma obtained from the patients) and the cross-validation between the results from C-CSID ImmunoSphers and E-CSID ImmunoSpheres (A2 and B2). The isolated CTCs and CTXs were verified by whole-body fluorescence imaging (only model CTC/CTX samples; A1-2 and B1-2), plate reading assay (only model CTC/CTX samples; A1-3 and B1-3) before bead degradation. Afterward, C-CSID ImmunoSphere and ECSID ImmunoSphere were degraded for maker recovery, and the isolated CTCs and CTXs were analyzed by immunofluorescence(CTC; A1-5 and A2-5) and nanoparticle tracking analysis(CTX; B1-5 and B2-5), respectively. Lastly, the results between CTC study (A2-5) and CTX study (B2-5) were compared in order to verify the correlation between two circulating markers.

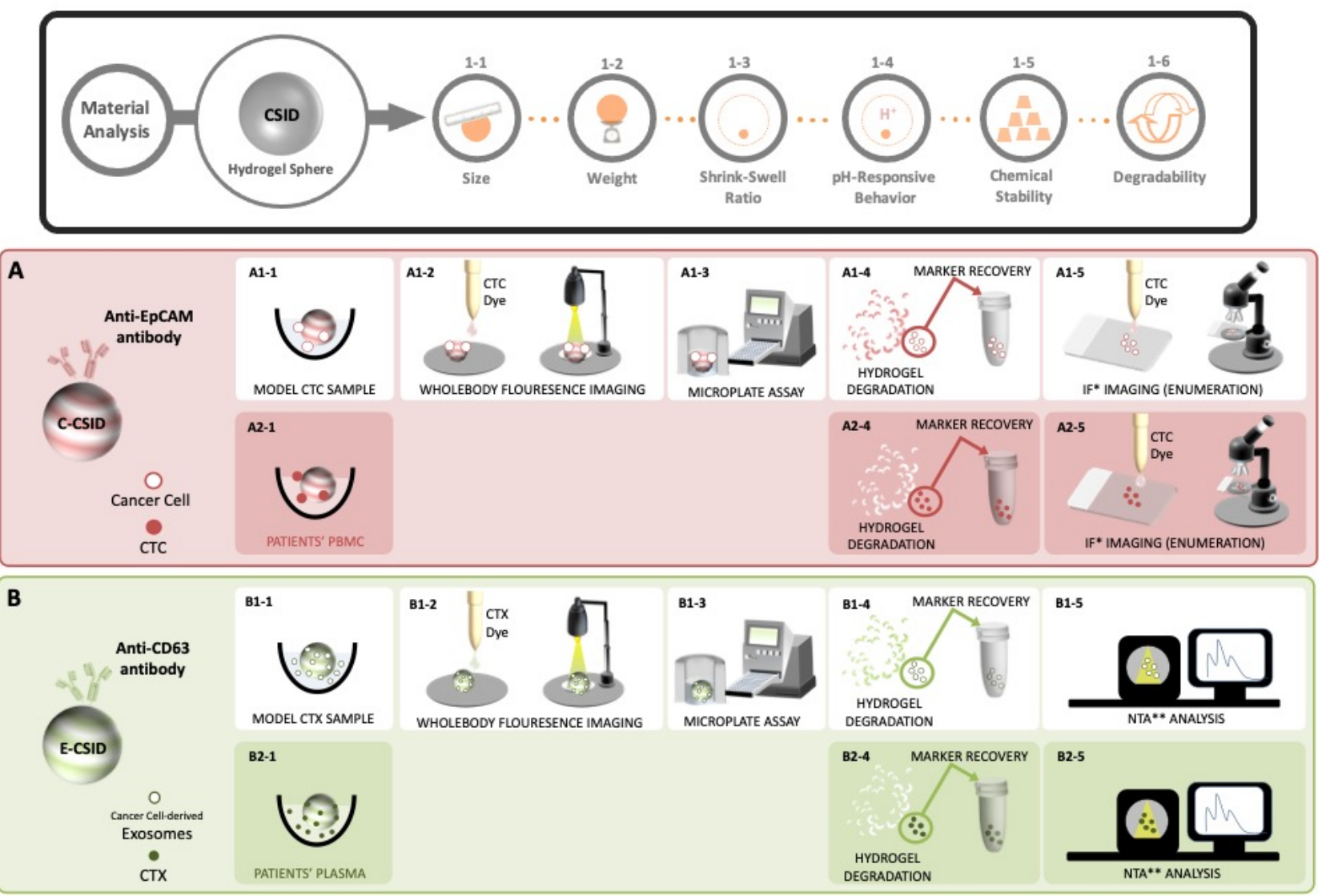

Figure S1. An overview of the experimental procedure for the study. 


\section{S2. Preparation of the CSID Hydrogel Spheres}

\section{S2-1. Hydrogel Characteristics}

The CSID hydrogel spheres were prepared via ionotropic gelation with divalent cations, followed by further hardening process. Figure S2(a) and S2(b) show the swollen state and shrunken state of the CSID hydrogel spheres. As it can be seen in Figure 2(c) (CA spheres) and 2(d) (CSID spheres), those two spheres are similar to each other, in size and shape; but, the CSID spheres were slightly bigger when they were swollen. The present CSID hydrogels were very stable and thus it is possible to keep several months without damaging.

As we mentioned in the manuscript, we present $\mathrm{pH}$-responsive behavior of the CSID spheres, in the range from $\mathrm{pH} 3$ to $\mathrm{pH} 11$. After 2 hours of incubation in the solution having each $\mathrm{pH}$ level, the CSID spheres were shrunken at $\mathrm{pH} 3$ (to around $0.1 \mathrm{~mm}$ in diameter) and extremely swollen at $\mathrm{pH} 11$ (to about $4.2 \mathrm{~mm}$ in diameter) without showing dramatic change in their shape and diameter between $\mathrm{pH} 5$ and $\mathrm{pH}$ 9. The volume of the CSID spheres were dramatically changed below $\mathrm{pH} 3$ or above $\mathrm{pH} 11$ so that their volumetric changes can be easily observed with the naked eyes (Figure 2(e)). Next, we investigated the degradation behavior of the present CSID spheres. Figure 2(f) presents the photographic images of the CSID spheres under the chelating reaction of EDTA. For the gentle and soft degradation to preserve valuable markers, we chose the mildest condition for the clinical samples: $25 \mathrm{mM}$ EDTA solution under constant agitation at $25^{\circ} \mathrm{C}$. However, as we mentioned in the manuscript, the estimated half-life of the CSID spheres can be controlled by adjusting chelating conditions (e.g. temperature, $\mathrm{pH}$, chelator's concentration, etc.) if those conditions are proven safe and effective.
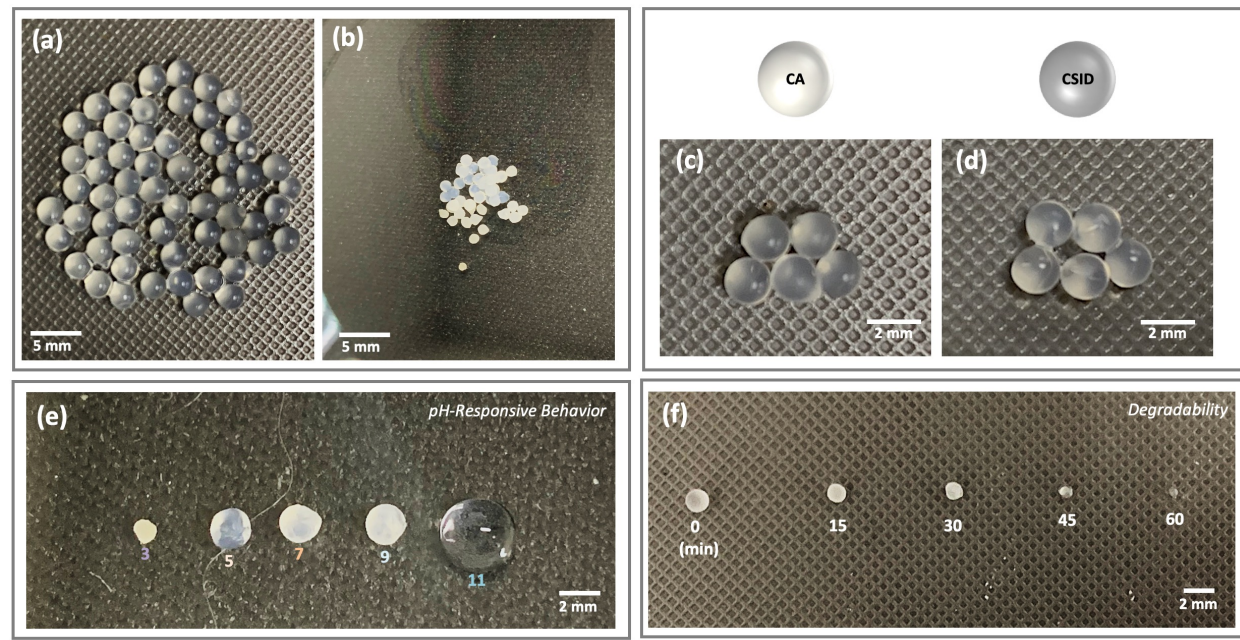

Figure S2. The photographic images of the present CSID hydrogel spheres: (a) CSID hydrogel at swollen state; (b) CSIDE hydrogel spheres at shrunken state; (c) SA hydrogel spheres at swollen state; (d) CSID hydrogel spheres at swollen state; (e) pH-responsive behavior of the CSID hydrogel spheres; (f) observation of degradation kinetics of the CSID hydrogel spheres. 


\section{S2-2. Basic Premise for the ImmunoSphere Design: Carrying Capacity}

The size of the prepared CSID sphere was in millimeter scale $(\mathrm{d}=2.41 \pm 0.14 \mathrm{~mm})$ at the normal swollen state. It is usual size of the alginate-based spheres when they are prepared by simple extrusion method (dripping in the gelation bath); the diameter of around 2.5 $\mathrm{mm}$ was easily achievable dimension without expansive tools. ${ }^{1,2}$ We did not precisely control the diameter of the CSID spheres because these millimeter-sized hydrogel spheres are suitable for the goal of this study: easy and simple operation (recognizable to the naked eyes, convenient handling with laboratory spatula, and centrifuge-free separation).

Then, we considered carrying capacity of a single CSID sphere, regarding the characteristics of targets of interest (TOI: CTC and CTX). The carrying capacity, which is originally established as an ecology term, means the number or quantity of people or things that can be conveyed or held by a vehicle or container. Later, scientists and engineers, especially in the field of environmental technology, borrowed this term to explain the maximum capability or containability of the proposed system (e.g. purification system, sewage disposal facilities.) In here, we borrowed this term again to estimate the optimal dimension for the CSID spheres: the maximum amount of TOI that can be isolated by a single CSID sphere. Because the surface area of the present CSID sphere is quite immense (approx. 18.25 $\mathrm{mm}^{2}$ ), we standardize the present method on a single sphere per a well (containing 1 milliliter of sample). Several assumptions have been involved for the following estimations: (a) we regarded that the CSID sphere as a perfect sphere which have plain and smooth surface without wrinkles, the surface area of the sphere. Accordingly, fixed diameter and surface area were put in the following calculation; (b) we also regarded CTC and CTX as a perfect sphere inscribed in the regular hexahedron (cube). The width, length, and height of the cube are identical to the largest size of each TOI (CTC $=20 \mathrm{um}$; CTX $=150 \mathrm{~nm})$; (c) during the antibody immobilization process (CSID sphere turns into CSID ImmunoSpheres), the loaded antibodies are enough to react to upper limit amount of TOI in 1 millimeter, and they immobilized evenly on the surface of CSID sphere, with an equal spacing; (d) we assumed that TOI cannot be penetrated into the CSID ImmunoSphere because they are much bigger than pore size of the present hybrid hydrogel (5 10 nm). Therefore, all the reaction between CSID ImmunoSphere (having antibodies) and TOI (presenting antigens) occurs at the interface of CSID sphere; (e) when TOI are isolated, they evenly occupy the surface of CSID ImmunoSphere, as a monolayer.

Under the aforementioned approximation theoretical carrying capacity of C-CSID ImmunoSphere, W-CSID ImmunoSphere, and ECSID ImmunoSphere was approximately 45,000 CTCs, $1.83 \times 10^{5} \mathrm{WBCs}$, and $8.11 \times 10^{8} \mathrm{CTX}$. Because there is no chance to happen this conjectural situation, thus we needed to set a standard in a feasible range. With a conservative assumption, we decided 1/100 level of the numbers calculated above, as a maximum carrying capacity of a single CSID sphere: approximately $450 \mathrm{CTCs}, 1.83 \times 10^{3} \mathrm{WBCs}$, and $8.11 \times 10^{6}$ CTXs. In conclusion, this result indicates that the surface area of the present CSID sphere is still enough to cover for the frequency range of TOI (1 10 CTCs and $\left.>10^{6} \mathrm{CTXs}\right)$. According to this assumption, we put only one CSID ImmunoSphere into well (containing 1 milliliter of sample). The WBCs (non-target background cells) are different issue in here because they are not TOI and we do not need to isolate all of them. We will further discuss the role of WBCs in Supporting Information S3-6. 


\section{S3. Model CTC/CTX Study}

\section{S3-1. Methods: Surface Modification of the CSID Hydrogel Spheres}

First, the spheres were slightly dehydrated and fully hydrated again by deionized water. Separately, $200 \mathrm{mM}$ of 1-ethyl-3-[3dimethylaminopropyl] carbodiimide (EDC) and $200 \mathrm{mM}$ of N-hydroxysulfosuccinimide (Sulfo-NHS) were dissolved in deionized water and mixed in a 1:1 ratio to activate EDC-NHS coupling. Then, the CSID spheres were incubated with the mixture under constant stirring at room temperature. Subsequently, we carefully washed the CSID spheres with deionized water so as not to damage the soft and swollen surface. Afterwards, the CSID spheres were kept in deionized water until further use.

\section{S3-2. Methods: Antibody Immobilization of the CSID Hydrogel Spheres}

The CSID spheres containing amine-reactive functional group were washed with deionized water, and then they were incubated with 1 $\mathrm{mg} / \mathrm{ml}$ of biotinylated BSA solution in $10 \mathrm{mM}$ Tris buffer, at $4^{\circ} \mathrm{C}$ for 1 hour. The unreacted molecules were removed by washing with Tris buffer and deionized water. Next, the identical procedure was repeated with $200 \mathrm{ug} / \mathrm{ml}$ of avidin in $10 \mathrm{mM}$ Tris buffer was for avidin-biotin binding. This reaction proceeded at $4{ }^{\circ} \mathrm{C}$ for $30 \mathrm{mins}$, and the unreacted avidin molecules also removed by the identical way to the previous step. Finally, biotinylated antibodies were introduced on the surface of the CSID spheres via avidin-biotin chemistry. As we described in the manuscript, total three types of antibodies utilized for the present study: anti-EpCAM antibody, anti-CD45 antibody, and anti-CD63 antibody. And each sphere was denoted as C-CSID ImmunoSpheres (anti-EpCAM antibody-immobilized CSID hydrogel spheres), E-CSID ImmunoSpheres (anti-CD63 antibody-immobilized CSID hydrogel spheres); and W-CSID ImmunoSpheres (anti-CD45 antibody-immobilized CSID hydrogel spheres). The loading amount for C-CSID ImmunoSpheres, WCSID ImmunoSpheres, and E-CSID ImmunoSpheres was $0.01 \mathrm{ug} / \mathrm{sphere,} 0.01 \mathrm{ug} / \mathrm{sphere}$, and $0.1 \mathrm{ug} / \mathrm{sphere}$, respectively. This antibodyto-sphere ratio was decided on the basis of the average surface area of the CSID spheres and amount of TOI $\left(1 \sim 10\right.$ CTCs and $>10^{6}$ CTXs). In order to control this particular antibody-to-sphere ratio, we standardized the entire antibody immobilization process on the small batch reaction. The reaction was conducted at $4^{\circ} \mathrm{C}$ for 1 hour, under the continuous agitation. Lastly, for preventing nonspecific adsorption, each sphere was treated with $1 \%$ BSA solution for 30 mins, followed by removing the unreacted antibodies. 


\section{S3-3. CTC Study: Competitive Binding Affinity Test}

In order to prove specific binding affinity, we measured the performance of the present CSID ImmunoSpheres under the complex environment. The control CSID spheres and C-CSID ImmunoSpheres (target isolation) and W-CSID ImmunoSpheres (non-target elimination) were simultaneously reacted with model CTC samples $\left(1 \times 10^{2}\right.$ cancer cells $/ \mathrm{ml}$ and $\left.1 \times 10^{6} \mathrm{WBCs} / \mathrm{ml}\right)$ in a single well. The reaction was carried out for 60 minutes, under continuous agitation. The purpose of this test is to estimate the cross-reactivity between C-CSID ImmunoSpheres and W-CSID ImmunoSpheres. In other words, we enumerated the non-specifically adsorbed WBCs on CCSID ImmunoSpheres and the non-specifically adsorbed cancer cells in W-CSID ImmunoSpheres, respectively. The tests were repeated for ten times $(n=10)$. As shown in Figure S3, approximately $88.89 \%$ of the cancer cells were found on the C-CSID ImmunoSpheres; in the meantime, $4.21 \%$ and $6.90 \%$ of cancer cells were found on the W-CSID ImmunoSpheres and control CSID spheres. Likewise, 93.49\% of the WBCs were found on the W-CSID ImmunoSpheres; but $1.83 \%$ and $4.68 \%$ of cancer cells were found on the C-CSID ImmunoSpheres and control CSID spheres. These results indicated that C-CSID ImmunoSpheres and W-CSID ImmunoSpheres have strong affinity to cancer cells and WBCs, respectively. The non-specifically adsorbed WBCs on C-CSID ImmunoSpheres was estimated to be 0.11 per $\mathrm{mm}^{2}$, and the non-specifically adsorbed cancer cells in W-CSID ImmunoSpheres was estimated to be 0.16 per $\mathrm{mm}^{2}$. Both are relatively lower than the non-specifically adsorbed cancer cells or WBCs on the control CSID spheres. This result may be explained by the fact that not only innate hydrophilicity of a hydrogel sphere also the protein-based outside layer (antibody-immobilized layer and BSA blocking layer) of the immunospheres contributed to the prevention of non-specific adsorption at a certain degree.

(a)

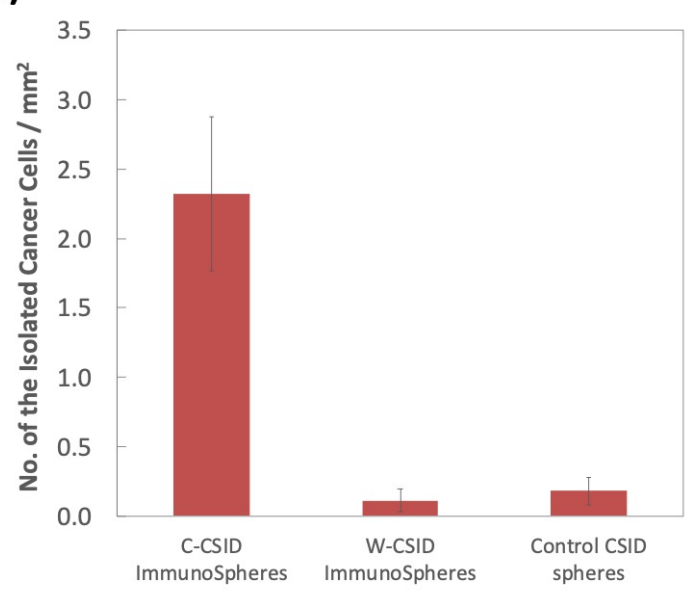

(b)

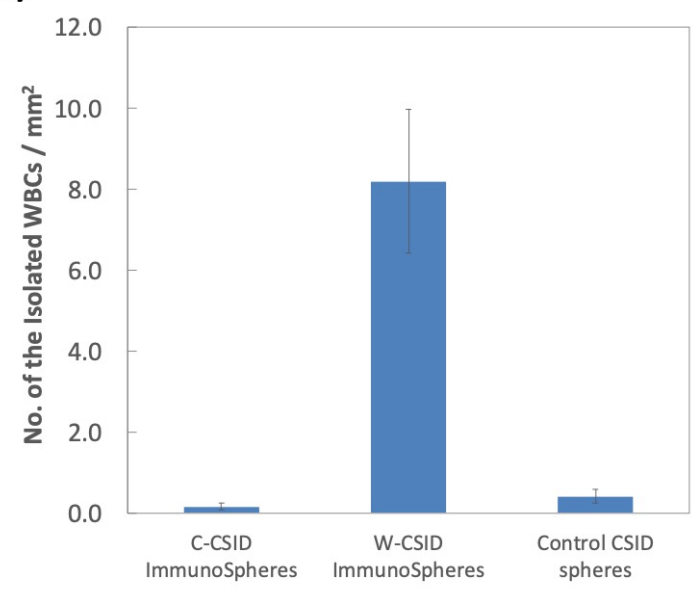

Figure S3. Competitive binding affinity test for the C-CSID ImmunoSpheres: (a) number of the isolated cancer cells on control CSID spheres, C-CSID immunospheres and W-CSID immunospheres; (b) number of the isolated WBCs on control CSID spheres, C-CSID immunospheres and W-CSID immunospheres. The tests were repeated for ten times $(n=10)$. 


\section{S3-4. CTC Study: Capture Efficiency}

In the last decade, several evaluation criteria have been suggested: capture (isolation) efficiency, release (retrieval) efficiency, viability, purity, and so on. Among them, capture efficiency has been considered as most important criteria in the CTC research. It is simply defined as the number of the captured (isolated) cancer cells divided by the spiked cancer cells. Sometimes this term is used without clear differentiating between intermediate "just-capturing" state (e.g. microfluidics or cell filter) and final "ready-to-analyze" state (CellSearch ${ }^{\circledast}$ or MagSweeper). In our case, the count was conducted at the final state (A1-5 in Figure S1). After 60 minutes of onesphere-per-one-well reaction, the results from C-CSID ImmunoSpheres $(n=10)$ were varied along with the cancer cell type of model CTC sample: MCF-7 (48.6 $\pm 13.5 \%$ /sphere); SK-BR-3 (52.2 $\pm 9.8 \% /$ sphere); MDA-MB-231 (28.1 $\pm 6.8 \% /$ sphere $)$. In numbers, these results seem to be low to the previously reported platforms (Table S1). However, there are three points need to be considered: (a) capture efficiency could be varied according to the experimental condition, even with the identical tools. For example, there have been several reports that this value was affected by cancer cell type, ${ }^{3}$ the initial number of the spiked cell, ${ }^{4}$ the amount of the non-target background cells (WBCs) ${ }^{5}$ the sample processing rate,${ }^{6,7}$ surface area,${ }^{7}$ and so on. We were thinking once we set the specific binding (SB) per unit area, with consistency, we can optimize the performance by the modulation of surface area. For example, according to our experience, the number itself increased when we put two or three sphere per well; (b) as we mentioned above, the capture efficiency of this study was calculated at the already retrieved state. It seems to be similar to the magnetic immunobeads-based method, but the present methods offer ferrofluid-free enriched sample; (c) simultaneous isolation with CTX is the key to overcome the traditional concept of CTC researches. Because CTCs are extremely rare and hard to isolate, co-profiling with the abundant CTXs from the same sample could be the reasonable way to gathering disease-related information.

Table S1. Comparison of Capture Efficiency with the well-established Affinity-based CTC Isolation Methods ${ }^{3-10}$

\begin{tabular}{|c|c|c|c|c|c|c|c|c|c|c|c|}
\hline \multirow{3}{*}{ Type } & \multirow{3}{*}{ Description } & \multirow{3}{*}{ Tool } & \multicolumn{5}{|c|}{ Model CTC Sample Preparation } & \multirow{3}{*}{$\begin{array}{c}\text { Sample } \\
\text { Processing } \\
\text { Time* } \\
\text { (min) }\end{array}$} & \multirow{3}{*}{$\begin{array}{l}\text { Capture } \\
\text { Efficiency }\end{array}$} & \multirow{3}{*}{$\begin{array}{c}\text { Retrieval } \\
\text { Capability }\end{array}$} & \multirow{3}{*}{ Note } \\
\hline & & & \multirow{2}{*}{ Cond. } & \multirow{2}{*}{$\begin{array}{c}\text { Volume } \\
\text { (mL) }\end{array}$} & \multirow{2}{*}{ Cell Type } & \multicolumn{2}{|c|}{ Cell Concentration } & & & & \\
\hline & & & & & & Target & Non-target & & & & \\
\hline \multirow{8}{*}{ Batch } & \multirow{8}{*}{$\begin{array}{l}\text { Immuno- } \\
\text { magnetic } \\
\text { Beads }\end{array}$} & \multirow{5}{*}{ CellSearch ${ }^{\circledR 3,4,9}$} & WB & 7.5 & MCF-7 & 150 & $\mathrm{WBC}+\mathrm{RBC}$ & $<60$ & $71.1 \pm 2.9 \%$ & \multirow{5}{*}{ Yes and $\mathrm{No}^{*}$} & $\mathrm{n}=14$ \\
\hline & & & \multirow{2}{*}{ WB } & 7.5 & MCF-7 & 240 & $\mathrm{WBC}+\mathrm{RBC}$ & $<60$ & $89 \pm 13 \%$ & & $\mathrm{n}=3$ \\
\hline & & & & 7.5 & MDA-MB-231 & 240 & $\mathrm{WBC}+\mathrm{RBC}$ & $<60$ & $12 \pm 15 \%$ & & $\mathrm{n}=3$ \\
\hline & & & \multirow{2}{*}{ WB } & 7.5 & SK-BR-3 & 47 & $\mathrm{WBC}+\mathrm{RBC}$ & $<60$ & $15.8 \%$ & & $\mathrm{n}=5$ \\
\hline & & & & 7.5 & SK-BR-3 & 258 & $\mathrm{WBC}+\mathrm{RBC}$ & $<60$ & $85.0 \%$ & & $\mathrm{n}=5$ \\
\hline & & \multirow{3}{*}{ MagSweeper ${ }^{5}$} & \multirow[t]{2}{*}{ PBS } & 9.0 & HLA-A2 & 50 & WBC $\left(2 \times 10^{5}\right)$ & 60 & $>55 \%$ & \multirow{3}{*}{ Yes and $\mathrm{No}^{*}$} & $\mathrm{n}=3$ \\
\hline & & & & 9.0 & & 50 & WBC $\left(2 \times 10^{6}\right)$ & 60 & $>50 \%$ & & $\mathrm{n}=3$ \\
\hline & & & WB & 3.0 & MCF-7 & 50 & $\mathrm{WBC}+\mathrm{RBC}$ & 60 & $59.0 \pm 27.0 \%$ & & $\mathrm{n}=9$ \\
\hline \multirow{11}{*}{ Flow } & \multirow{11}{*}{$\begin{array}{l}\text { Micro- } \\
\text { fluidics }\end{array}$} & \multirow{6}{*}{ CTC-Chip ${ }^{6}$} & \multirow{5}{*}{ PBS } & N/A & PC3-9 & $100 / \mathrm{mL}$ & - & $\sim 160$ & $>75 \%$ & \multirow{6}{*}{ No } & $\mathrm{n}=3$ \\
\hline & & & & $\mathrm{N} / \mathrm{A}$ & SK-BR-3 & $100 / \mathrm{mL}$ & - & $\sim 160$ & $>70 \%$ & & $n=3$ \\
\hline & & & & $\mathrm{N} / \mathrm{A}$ & $\mathrm{T}-24$ & $100 / \mathrm{mL}$ & - & $\sim 160$ & $>75 \%$ & & $\mathrm{n}=3$ \\
\hline & & & & $\mathrm{N} / \mathrm{A}$ & NCI-H-1650 & $100 / \mathrm{mL}$ & - & $\sim 120$ & $>60 \%$ & & $\mathrm{n}=3$ \\
\hline & & & & $\mathrm{N} / \mathrm{A}$ & NCI-H-1650 & $100 / \mathrm{mL}$ & - & $\sim 80$ & $>60 \%$ & & $\mathrm{n}=3$ \\
\hline & & & WB & N/A & NCI-H-1650 & $50 \sim 50000$ & $\mathrm{WBC}+\mathrm{RBC}$ & $\sim 160$ & $>60 \%$ & & $\mathrm{n}=3$ \\
\hline & & \multirow{2}{*}{ HB-Chip ${ }^{7}$} & \multirow{3}{*}{ WB } & 4.0 & PC-3 & $1000 / \mathrm{mL}$ & $\mathrm{WBC}+\mathrm{RBC}$ & 160 & $79.0 \pm 4.5 \%$ & \multirow{3}{*}{ No } & $\mathrm{n}=8$ \\
\hline & & & & 4.0 & $\mathrm{PC}-3$ & $1000 / \mathrm{mL}$ & $\mathrm{WBC}+\mathrm{RBC}$ & 96 & $>40 \%$ & & $\mathrm{n}=8$ \\
\hline & & (Large HB-Chip) & & 4.0 & $\mathrm{PC}-3$ & $1000 / \mathrm{mL}$ & $\mathrm{WBC}+\mathrm{RBC}$ & 160 & $91.8 \pm 5.2 \%$ & & $\mathrm{n}=6$ \\
\hline & & MicroGEDI & PBS & 1.0 & $\mathrm{LNCaP}$ & $150 \sim 220$ & - & 60 & $>97 \pm 3 \%$ & & $\mathrm{n}=7$ \\
\hline & & Chip ${ }^{10}$ & WB & 1.0 & $\mathrm{LNCaP}$ & $150 \sim 220$ & $\mathrm{WBC}+\mathrm{RBC}$ & 60 & $>85 \pm 5 \%$ & No & $\mathrm{n}=7$ \\
\hline & & & & 1.0 & MCF-7 & 100 & WBC $\left(10^{6}\right)$ & 60 & $48.6 \pm 13.5 \%$ & & $\mathrm{n}=10$ \\
\hline Batch & $\begin{array}{l}\text { The Present } \\
\text { Study }\end{array}$ & $\begin{array}{l}\text { C-CSID } \\
\text { ImmunoSphere }\end{array}$ & PBS & 1.0 & SK-BR-3 & 100 & WBC $\left(10^{6}\right)$ & 60 & $52.2 \pm 9.8 \%$ & Yes & $\mathrm{n}=10$ \\
\hline & & & & 1.0 & MDA-MB-231 & 100 & WBC $\left(10^{6}\right)$ & 60 & $28.1 \pm 6.8 \%$ & & $\mathrm{n}=10$ \\
\hline
\end{tabular}




\section{S3-5. CTC Study: Other Major Criteria}

Next, we summarized overall performance of the present hydrogel-based method using the other major criteria mentioned in the previous literatures. The comparison with the other platforms was conducted on the identical condition, containing background cells; thus, we exclude the data from PBS-based spiking test without adding WBCs. For proper comparison, the initial WBC and RBC level were presumed to be $5.0 \times 10^{6} / \mathrm{mL}$ and $5.0 \times 10^{9} / \mathrm{mL}$, respectively. First, we tested viability of the present method, and the viability means the amount of the live CTCs among the isolated CTCs. With the current method, viability was estimated to be $90.8 \pm 2.4 \%$ ( $\mathrm{n}=10$ ). Afterward, the purity and enrichment factor of the present method were also evaluated. The purity means the ratio between the background cells and the cancer cells in the final sample. It is calculated as follow:

$$
\text { Purity }(\%)=\frac{(\text { Final No. of the Cancer Cells })}{(\text { Final No. of the Cells })} \times 100(\%)
$$

Meanwhile, enrichment yield or enrichment factor was sometimes mentioned as a convenient concept; it enables us to understand the performance of the proposed tools, with a simple number. Unlike other criteria, enrichment yield is not easily be exaggerated according to the initial experimental condition. Because it reflects the initial ratio between the background cells and the cancer cells, it is considered as more reliable concept, and it is calculated as follow:

$$
\text { Enrichiment Factor }=\frac{(\text { Initial No. of the Cells } \times \text { Fraction of the Cancer Cells })}{(\text { Final No. of the Cells } \times \text { Fraction of the Cancer Cells })}
$$

In this study, the purity was approximately $93.5 \pm 2.6 \%(\mathrm{n}=10)$ and enrichment factor was calculated to be $\sim 10^{5}$ level. These results indicate that the present method is advantageous in recovering highly purified samples. Among the previously published methods, the present CSID immunospheres showed a comparable performance characteristic to MagSweeper (high purity and high enrichment factor), with a similar strength and weakness. As a batch type reaction, the MagSweeper present applicability to the whole blood, while the present CSID immunospheres offer ferrofluid-free isolation method.

\begin{tabular}{|c|c|c|c|c|c|c|c|c|c|c|c|c|}
\hline \multirow{3}{*}{ Type } & \multirow{3}{*}{ Description } & \multirow{3}{*}{ Tools } & \multicolumn{4}{|c|}{ Model CTC Sample Preparation } & \multicolumn{6}{|c|}{ Evaluation Criteria** } \\
\hline & & & \multirow{2}{*}{$\begin{array}{l}\text { Whole } \\
\text { Blood" }\end{array}$} & \multirow{2}{*}{$\begin{array}{l}\text { PBS } \\
\text { Dilu } \\
\text { tion } \\
\end{array}$} & \multicolumn{2}{|c|}{$\begin{array}{l}\text { Background } \\
\text { Cells }\end{array}$} & \multirow{2}{*}{$\begin{array}{l}\text { Capture } \\
\text { Efficiency }\end{array}$} & \multirow[t]{2}{*}{ Viability } & \multirow{2}{*}{$\begin{array}{l}\text { Repeat- } \\
\text { ability }\end{array}$} & \multirow[t]{2}{*}{$\underset{* * *}{\text { Specificity }}$} & \multirow[t]{2}{*}{ Purity } & \multirow{2}{*}{$\begin{array}{c}\text { Enrichment } \\
\text { Factor }\end{array}$} \\
\hline & & & & & WBC & RBC & & & & & & \\
\hline \multirow{2}{*}{ Batch } & \multirow{2}{*}{$\begin{array}{l}\text { Immuno- } \\
\text { magnetic } \\
\text { Beads }\end{array}$} & CellSearch $^{\circledR 3,4,9}$ & $x$ & ० & $\circ$ & $x$ & $12 \sim 89 \%$ & $\mathrm{~N} / \mathrm{A}$ & $\sim 6.8 \%$ & $27 \sim 70 \%$ & $0.1 \sim 14.0 \%$ & $\sim 10^{4}$ \\
\hline & & MagSweeper ${ }^{5}$ & $\circ$ & 0 & 0 & o & $59 \%$ & $94 \%$ & $\sim 27.0 \%$ & $100 \%$ & $51 \sim 100 \%$ & $\sim 10^{8}$ \\
\hline \multirow{3}{*}{ Flow } & \multirow{3}{*}{$\begin{array}{l}\text { Micro- } \\
\text { fluidics }\end{array}$} & CTC-Chip ${ }^{6}$ & $x$ & ० & $\circ$ & $x$ & $60 \%$ & $>99 \%$ & N/A & $64 \sim 99 \%$ & $9 \sim 50 \%$ & $\sim 10^{4}$ \\
\hline & & HB-Chip ${ }^{7}$ & o & $x$ & o & ० & $40 \sim 92 \%$ & $95 \%$ & $4 \sim 5 \%$ & $93 \%$ & $14 \%$ & N/A \\
\hline & & $\begin{array}{l}\text { MicroGEDI } \\
\text { Chip }\end{array}$ & 0 & $x$ & 0 & 0 & $85 \%$ & $\mathrm{~N} / \mathrm{A}$ & $3 \sim 5 \%$ & $94 \%$ & $62 \sim 74 \%$ & $\mathrm{~N} / \mathrm{A}$ \\
\hline Batch & $\begin{array}{l}\text { The Present } \\
\text { Study }\end{array}$ & $\begin{array}{c}\text { C-CSID } \\
\text { ImmunoSphere } \\
\text { (per sphere) }\end{array}$ & $x$ & 0 & 0 & $x$ & $28 \sim 52 \%$ & $90.8 \%$ & $\sim 10.4 \%$ & $98.08 \%$ & $93.5 \%$ & $7.3 \times 10^{5}$ \\
\hline
\end{tabular}

Table S2. Performance Evaluation with the Major Criteria in CTC Research ${ }^{3-10}$ 


\section{S3-6. CTC Study: The Role of W-CSID ImmunoSpheres in this Study}

In the model CTC study, we included W-CSID ImmunoSpehers (anti-CD45 antibody-immobilized CSID spheres) together in the experimental design. However, we would like to emphasize that W-CSID ImmunoSpehers are just supporting players in this study; the real target is CTCs and thus the main player in here is C-CSID ImmunoSpehers.

However, the simultaneous usage of W-CSID ImmunoSpehers could be useful in the application with the real clinical sample. Usually, a milliliter of blood contains a few million $\sim 5 \times 10^{6}$ WBCs, but only $1 \sim 10$ CTCs are found in the same volume of blood. We prepared model CTC samples with 1: $10^{4}$ of CTC:WBC ratio $\left(1: 10^{4} ; 1 \times 10^{2}\right.$ cancer cells $/ \mathrm{ml}$ and $\left.1 \times 10^{6} \mathrm{WBCs} / \mathrm{ml}\right)$, but it is still quite exaggerated compared to the clinical samples $\left(1: 5 \times 10^{5} \sim 10^{6}\right)$. As mentioned in the Supporting Information S3-4, some previously reported articles have pointed out that the amount of non-target cells affect to the capture efficiency. ${ }^{5}$ Considering that the small sample volume of the present study, we assume that proper measure to adjust this ratio would be helpful. To address this problem, several CTC researches have focused on WBC eilimination. ${ }^{11-13}$ In case of the present study, there is no need to prepare another device or module for depleting WBCs from the sample (so-called "negative enrichment"), without spending extra processing time. W-CSID ImmunoSpheres were also prepared by the identical method, with replacing the type of antibodies. With an addition of one or two more spheres (W-CSID ImmunoSpehers), we anticipated that the WBCs' disturbance could be substantially lowered. In spite of the fact that the results from W-CSID ImmunoSpehers in this study was lower than expected (eliminate only 3-digit number of WBCs per sphere), we believe that the performance level could be enhanced by further optimization. Figure S4 shows a scheme for emerging positive selection (CTC isolation) and negative selection (WBC elimination), at the present setting. Because those two CSID immunospheres share preparation procedure, physical and chemical characteristics, reaction mechanism, logical ground, estimation, and processing time, the benefit of integration would be considerable, compared to the previous methods. In future investigations, it might be possible to use this strategy to revise CTC:WBC ratio to the feasible region (e.g. a single C-CSID ImmunoSpeher with several W-CSID ImmunoSpehers).

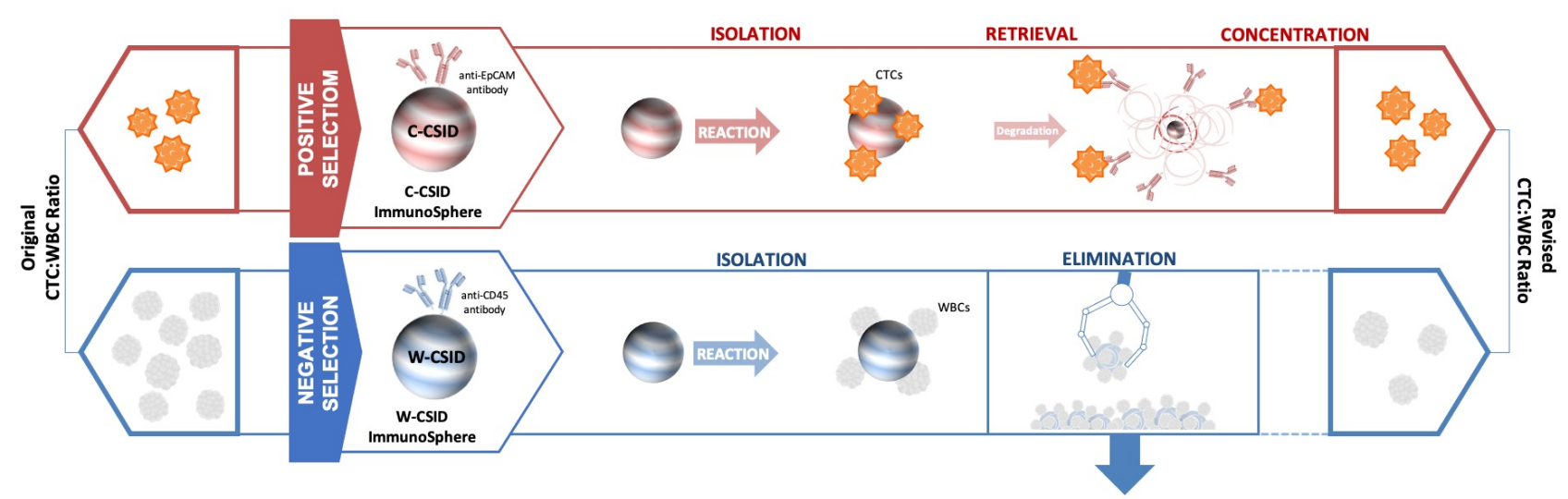

Figure S4. A scheme for potential application focusing on the role of W-CSID ImmunoSpehers. 


\section{S3-7. CTX Study: Capture Efficiency}

Basically, the capture efficiency for CTXs is difficult to be define because CTXs are abundant $\left(>10^{6}\right.$ per $\left.\mathrm{mL}\right)$ and impure targets. By definition, capture efficiency is calculated by the results using model sample (i.e. known sample: the sample solution containing the known number of targets). However, model CTX sample is not "known sample" because there is no way to measure exact initial concentration of CTXs. Therefore, some presumptions are required for the calculation of capture efficiency: (a) the estimation is based on the changes in particle concentration (per milliliter); (b) the initial amount of CTXs in the model CTX samples needs to be approximated by size-based measurement (nanoparticle tracking analysis), and the purity (the concentration of the CTX / the concentration of the CTX-sized vesicle) of initial sample and final sample is nearly the same; (c) these vesicles in the predetermined size range are conceded as "CTX-sized vesicles" because it is model CTX sample. The size gating for CTX-sized vesicles was in the range from $30 \mathrm{~nm}$ to $150 \mathrm{~nm}$, and the detailed information is described in the Supporting Information S4-4. Based on the aforementioned assumption, capture efficiency was calculated as follows:

$$
\text { Capture Efficiency }(\%)=\left[1-\frac{(\text { Final Concentration of CTX }- \text { sized vesicles })}{(\text { Initial Concentration of CTX }- \text { sized vesicles })}\right.
$$

In the present study, the capture efficiency of E-CSID ImmunoSpheres $(n=10)$ were varied along with the cancer cell type of model CTX sample: MCF-7 (38.6 $\pm 11.1 \%$ /sphere); SK-BR-3 (59.4 $\pm 16.8 \% /$ sphere); MDA-MB-231 (27.7 $\pm 12.6 \% /$ sphere). These numbers seem to be somewhat underestimated value because of the initial composition of model CTX sample (media after 24 hours of cancer cell culture). Because we assume the purity (the concentration of the CTX / the concentration of the CTX-sized vesicle) of initial sample and final sample is nearly the same, the enrichment performance could not be precisely reflected. In this context, we need to reconsider the purpose of the CTX isolation study. Since they are abundant target, it is not necessary to isolate all of them. For example, about $30 \%$ of the recovered CTXs means over more than $1.5 \times 10^{5} \mathrm{CTXs} / \mathrm{mL}$, in numbers, with a highly enriched form.

For this reason, we have so far investigated CTX separation techniques and also developed some new criteria for the accurate evaluation, in order to compensate the limitation of size-based measurement of CTX concentration: background subtraction efficiency (BSE), separation factor, CTX enrichment ratio, and so on. ${ }^{14}$ We provided additional description regarding these supporting criteria in the next chapter (Supporting Information S3-8). 


\section{S3-8. CTX Study: Other Major Criteria}

First, background subtraction efficiency (BSE) indicates the degrees of proper elimination of non-target vesicles. Because there have never been reported CTX-like vesicles larger than $200 \mathrm{~nm}$, the elimination of those impurities is also an important criterion for the evaluation of ability to obtain highly purified CTX samples, BSE(\%) is calculated as follow:

$$
\text { Background Subtraction Efficiency }(\%)=\left[1-\frac{(\text { Final Concentration of non }- \text { target Vesicles })}{(\text { Initial Concentration of non }- \text { target Vesicles })}\right]
$$

Meanwhile, Separation factor (SF), originally a chemistry term referring the efficiency of the separation process, is utilized in order to verify the possibility of efficient separation. It is the quotient of the ratio of a certain component to the sum of other components before and after a separation process. In here, separation factor is calculated based on the capture efficiency and background subtraction efficiency; thus, the smaller the factor is, the greater the efficiency of the separation is.

$$
\text { Separation Factor }=\frac{(1-\text { Background Substraction Efficiency) }}{(\text { Capture Efficiency })}
$$

As a result, the BSE of E-CSID ImmunoSpheres is: MCF-7 (84.4 $\pm 7.6 \%$ /sphere); SK-BR-3 (57.6 $\pm 4.8 \%$ /sphere); MDA-MB-231 $(43.8 \pm 11.1 \%$ /sphere). There results mean that $43.8 \sim 84.4 \%$ of vesicles, which is clearly not exosome, had been depleted after the reaction with E-CSID ImmunoSpheres. These results can be converted as separation factor: MCF-7 (0.40); SK-BR-3 (0.71); MDA-MB231 (1.65). These results present that the performance of E-CSID ImmunoSpheres is effective against MCF-7-derived CTXs, while it is relatively ineffective against MDA-MB-231-derived CTXs. Because anti-CD63 antibodies are immobilized, it might be speculated that different cancer cells excreted different types of CTXs, having the characteristics of mother cells.

\begin{tabular}{|c|c|c|c|c|c|c|c|c|}
\hline \multirow[b]{2}{*}{ Type } & \multirow[b]{2}{*}{ Description } & \multirow[b]{2}{*}{ Tools } & \multicolumn{2}{|c|}{ Model CTX Sample } & \multicolumn{3}{|c|}{ Evaluation Criteria } & \multirow[b]{2}{*}{ Note } \\
\hline & & & Origin & $\begin{array}{c}\text { Volume } \\
(\mathrm{mL})\end{array}$ & $\begin{array}{l}\text { Capture } \\
\text { Efficiency }\end{array}$ & $\begin{array}{c}\text { Background } \\
\text { Subtraction } \\
\text { Efficiency }\end{array}$ & $\begin{array}{c}\text { Separation } \\
\text { Factor }\end{array}$ & \\
\hline \multirow{3}{*}{ Batch } & \multirow{3}{*}{$\begin{array}{c}\text { The Present } \\
\text { Study }\end{array}$} & \multirow{3}{*}{$\begin{array}{c}\text { E-CSID } \\
\text { ImmunoSphere } \\
\text { (per sphere) }\end{array}$} & MCF-7-derived & 1.0 & $38.6 \pm 11.1 \%$ & $84.4 \pm 7.6 \%$ & 0.40 & $(\mathrm{n}=5)$ \\
\hline & & & SK-BR-3-derived & 1.0 & $59.4 \pm 16.8 \%$ & $57.6 \pm 4.8 \%$ & 0.71 & $(\mathrm{n}=5)$ \\
\hline & & & MDA-MB-231-derived & 1.0 & $27.7 \pm 12.6 \%$ & $43.8 \pm 11.1 \%$ & 1.65 & $(\mathrm{n}=5)$ \\
\hline
\end{tabular}

Table S3. Performance Evaluation with the Major Criteria in CTX Research 


\section{S3-9 CTC/CTX Study: Colorized FE-SEM images of the CSID Hydrogel ImmunoSpheres}

The FE-SEM images of isolated cancer cells and exosomes using the CSID hydrogel ImmunoSpheres have been presented in Figure 4. Because the detailed figure of them is not easily recognized due to the inherent wrinkles of the CSID hydrogels, we presented the colorized images together in order to help the readers understand. In this step, we utilized Adobe Photoshop CS6 (Adobe, USA) for post-processing of the images. Briefly, we roughly selected the Lasso Tool in order to distinguish target-isolated region. The selected area was smoothed by the function of Feather, and then made as a new layer. We utilized each color as a sort of symbol in our schematic diagram: red and blue, and green represents cancer cells, white blood cells, and exosomes, respectively. Therefore, we used the color symbols into the newly created layer, and the edges parts of the cells were carefully refined with the eraser. Lastly, we merged the modified layer with the background, and degree, magnitude, and saturation were properly adjusted.

\section{S3-10. CTC/CTX Study: FE-SEM images of the CSID ImmunoSpheres after Natural Air Drying}

The multi-step dehydration process using organic solvent is unavoidable choice for the preparation of FE-SEM imaging. However, these procedures are unfavorable in many bio-applications because of the possibility of target loss or damage. For the circulating markers isolated on the outer surface of the CSID ImmunoSpheres, we have the same concerns as well. Therefore, we prepared samples for FESEM through natural air drying. Briefly, the CSID ImmunoSpheres after isolation process were kept in shade for overnight. The temperature and humidity were not precisely controlled. In the next morning, we found that the spheres were quite shrunken. The osmium coating process was proceeded in the same manner (3.0-nm thickness). As shown in Figure S5, the cells were partly dehydrated, but there were distinct differences in CTCs (irregular-shaped) and WBCs (round-shaped). The inherent wrinkled surface of the CSID ImmunoSpheres had been disappeared on the dehydrated hydrogel spheres, and drying shrinkage cracks were found.

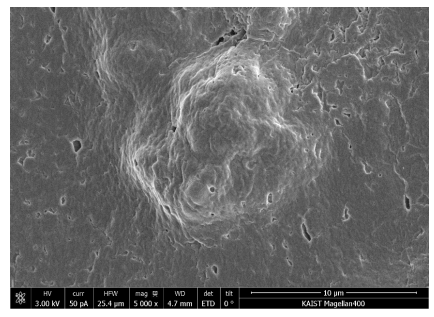

(a)

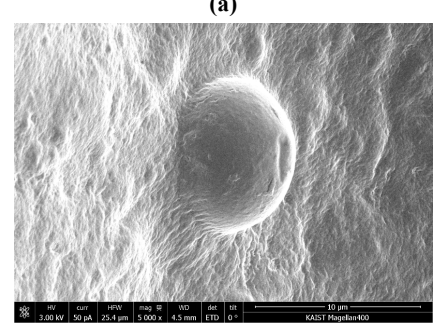

(c)

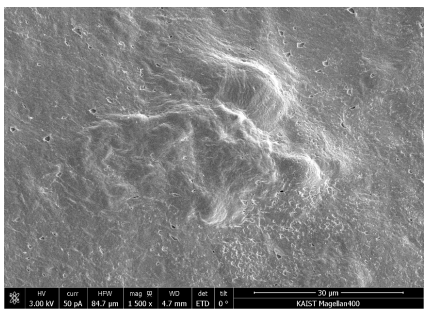

(b)

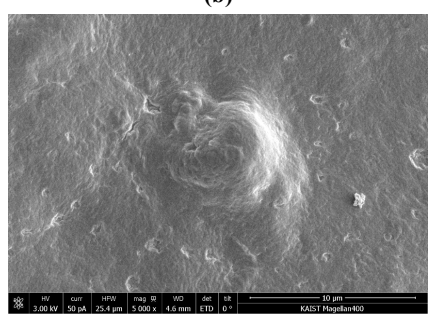

(d)

Figure S5. FE-SEM images of the CSID hydrogel ImmunoSpheres after natural air drying: (a and b) The isolated cancer cells on the surface of the C-CSID ImmunoSpheres; (c and d) The eliminated WBC on the surface of the W-CSID ImmunoSpheres. 


\section{S4. Clinical CTC/CTX Study}

\section{S4-1. Methods: Immunofluorescence Staining for CTCs}

The prepared cell-mounted slides were fixed with $4 \%$ paraformaldehyde for 30 minutes. The solution was gently aspirated, and the cells at the slide glass were immediately rinsed with PBS solution three times for 5 min each. Next, permeabilization and blocking processes were sequentially done for $30 \mathrm{~min}$ each, using Triton X-100 (Fisher Scientific) and PBS solution containing 3\% BSA solution, respectively. Finally, cells were labelled using immunofluorescence staining solution containing FITC-conjugated anti-cytokeratin (15:1000 diluted in PBS, Cat.\# 130-080-101, MACS Miltenyi Biotec.), PE-conjugated mouse anti-human CD45 (30:1000 diluted in PBS, Cat.\# 555483, BD Pharmingen), Alexa fluor ${ }^{\circledR}$ 647- conjugated anti-human EpCAM (15:1000 diluted in PBS, Anti-CD326, Cat.\#324212, BioLegend), and DAPI (10:1000 diluted in PBS D1306, Life Technologies) for 1 hour. After washing 3 times with PBS solution and final aspiration, we acquired cell images and identified using MetaMorph software (Molecular Devices, USA). All immunofluorescent cells were examined considering both the staining criteria (Cytokeratin+/DAPI+/CD45-) and the morphological features, such as nucleus-to-cytoplasm ratio and size.

\section{S4-2. Methods: Immunofluorescence Staining for CTXs}

We perform the immunofluorescence staining of the isolated CTXs to evaluate cancer-associated marker expression and epithelial/mesenchymal properties. The E-cadherin and vimentin, expressed on epithelial and mesenchymal CTXs, were chosen as the staining markers expressed on the surface. After fixation step, the E-CSID ImmunoSpheres were labeled for 1hr with the staining dye containing Alexa fluor ${ }^{\circledR}$ 488-conjugated E-cadherin and PE-conjugated anti-human vimentin. After washing out excess dyes three times with PBS, we verified the labeled CSID immunospheres using fluorescence imaging. 


\section{S4-3. CTC Study: Immunofluorescence Image of the Isolated CTCs}

As we described in the manuscript, the average 10.8 \pm 5.9 CTCs were founded in 1 milliliter of patients' blood from the five different colorectal patients with stage IV (CC1, CC2, CC3, CC4, and CC5). The verification of the immunostained slide was conducted via the criteria of the FDA-approved technique, CellSearch ${ }^{\circledR}(\mathrm{CK}+/ \mathrm{DAPI}+/ \mathrm{CD} 45-)$. Among the isolated CTCs by the C-CSID ImmunoSpheres, we selected several extraordinary cases as a representative image: CK(-) CTC and Dual(+) CTCs. These results reveal the presence of heterogeneous CTCs in the real patients' blood.
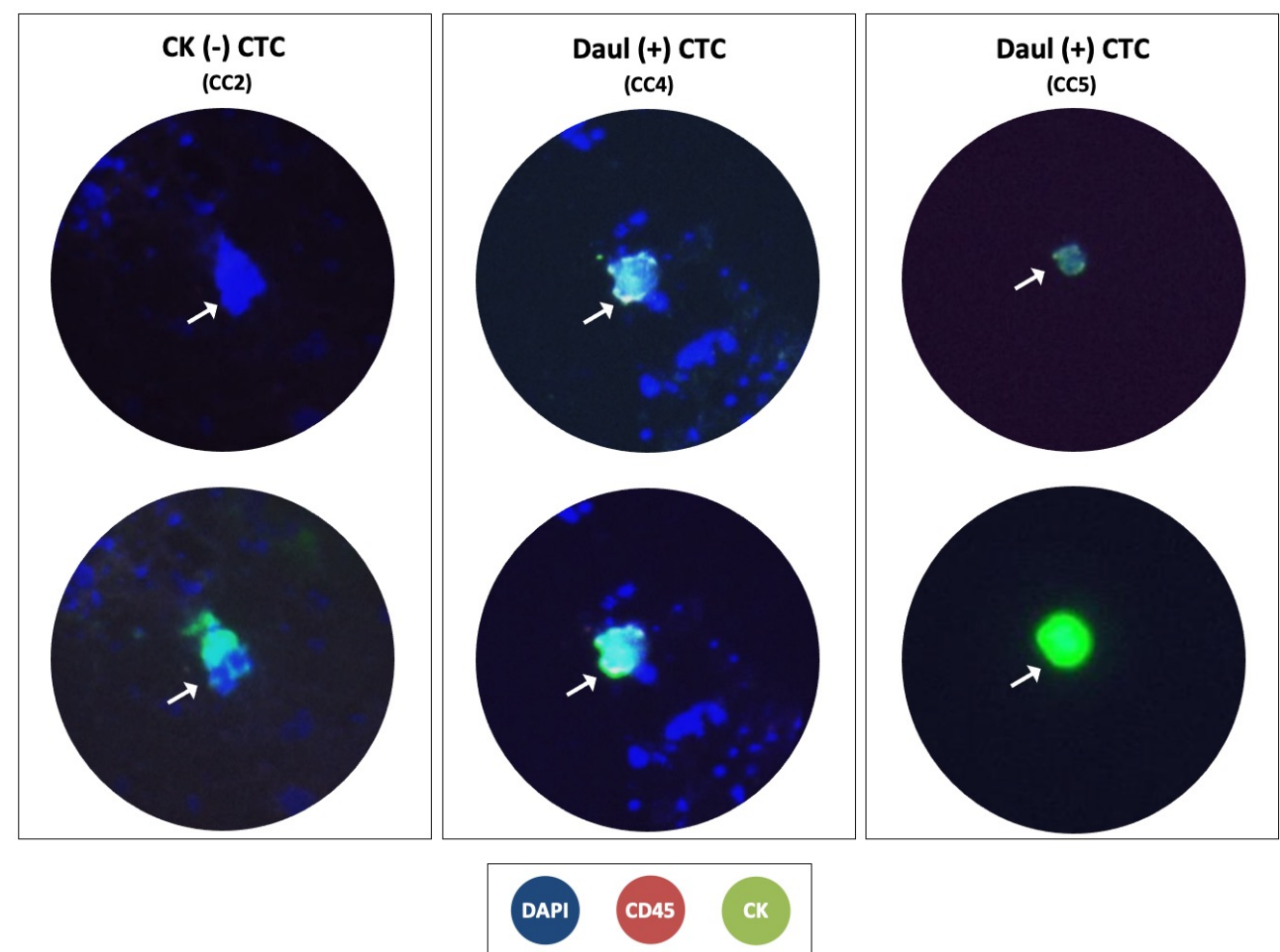

Figure S6. The representative images of the heterogeneous CTCs isolated by the C-CSID ImmunoSpheres. 


\section{S4-4. CTX Study: Estimation of Cancerous Exosome}

One of the difficulties in developing screening methodologies for circulating exosome is size matter. Recent studies have proposed different standard in the size gating of exosome: from narrowest $(50 \sim 100 \mathrm{~nm})^{15-17}$ to widest $(30 \sim 200 \mathrm{~nm}) .^{4-5}$ Plus, many researchers have also pointed out there are diverse contents in the reported range: protein aggregates, liposome, exosome-like vesicles (20 50 nm), membrane particle $(50 \sim 80 \mathrm{~nm})$, ectosome $(100 \sim 150 \mathrm{~nm})$, apoptotic vesicles $(50 \sim 1,000 \mathrm{~nm})$, micro-vesicles $(100 \mathrm{~nm} \sim 1,000 \mathrm{~nm})$, and so on. For these reasons, we need to clarify cancerous exosome-like particles from all of the exosome-like particles; in this study, exosome is defined as follow:

$$
\text { (Total) Exosome }=\frac{(\text { The vesicles in the size range of exosome })}{(\text { The vesicles collected by anti-CD63 antibody) }}
$$

Because normal cells also secrete exosomes, we make an effort to estimate the number of cancerous exosomes among total exosomesized particles. Therefore, we quantified surface protein expression and transformed the value as relative expression level.

$$
\text { Cancerous Exosome }=(\text { Total Exosome }) \times(\text { Relative Level of Protein Expression })
$$

The equation is based on the hypothesis that the number of cancerous exosomes is proportional to the increment of the signal from marker expression. However, it is not accurate because it depends on indirect estimation. As an alternative way, we proposed a concept of "E-M index," and it will be further discussed in the next section. 


\section{S4-5. CTX Study: E-M Index}

As we described in the previous section, it is difficult to define exosome with size gating only. In addition, normal (or non-cancerous) cells also secrete exosomes; thus, healthy donors may have a higher exosome level compared to cancer patients. In order to compensate the effect from normal exosome, we proposed a concept of "E-M index," and it is calculated as follow:

$$
\mathrm{E}-\mathrm{M} \text { Index }=\frac{(\text { Intensity of Mesenchymal Marker }(+) \text { Exosomes })}{(\text { Intensity of Epiterial Markers }(+) \text { Exosomes })}
$$

We chose e-cadherin and vimentin as an indicator of epithelial-like exosomes and mesenchymal-like exosomes, respectively. Because they are utilized for the identification of epithelial cells or mesenchymal cells, we assumed that the characteristics of cell-derived exosomes can be also evaluated. Even though it is still hard to estimate accurate portion of cancerous exosome among total exosomesized particles, at least we can approximate 'mesenchymalness' of the retrieved exosomes. An index smaller than 1.0 indicates that there are more epithelial-like exosomes than mesenchymal-like exosomes; on the other hand, an index greater than 1.0 indicates that there are more mesenchymal-like exosomes than epithelial-like exosomes. For example, in our study, five different colorectal patients (CC1, CC2, CC3, CC4, CC5) had $0.61,0.89,1.08,0.92,0.79$ of E-M index, respectively. These results are not accord with exosome concentration of each patient; but they showed similar tendency with the number of the retrieved CTCs from each patient's sample.

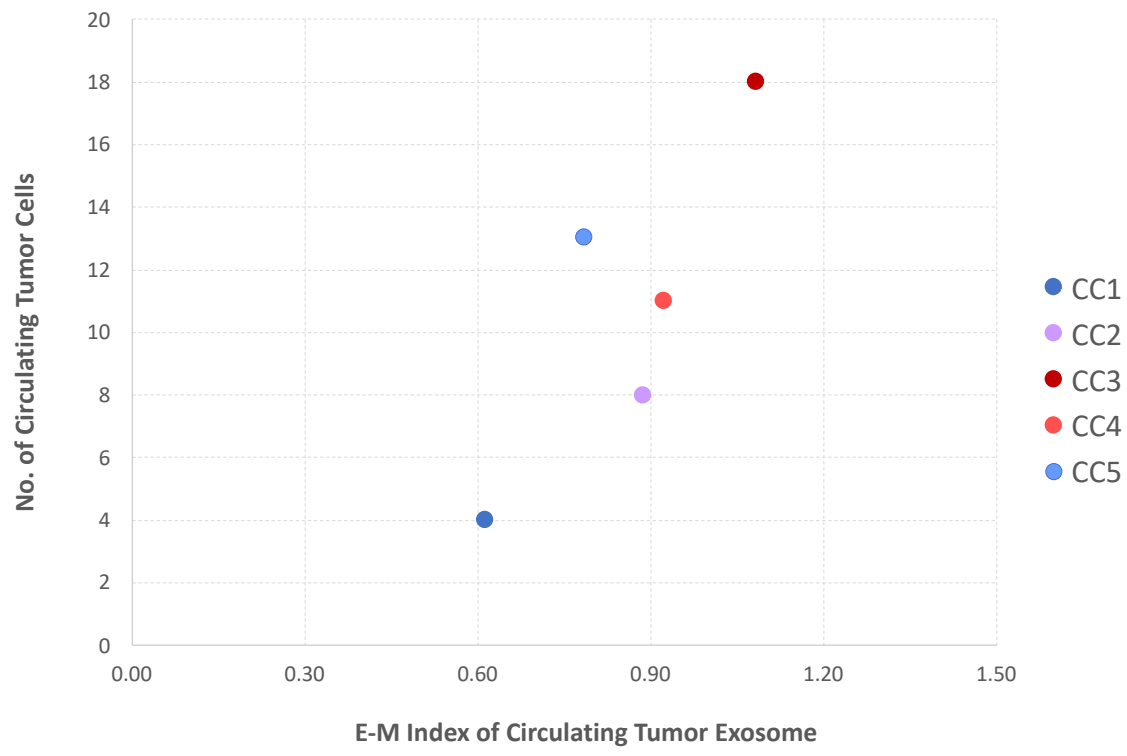

Figure S7. The estimation of the relevance between the number of the CTCs and E-M index of the CTX. 


\section{S4-6. CTX Study: Particle Size Distribution (PSD)-based CTX Analysis}

The particle-size distribution (PSD) is a list of values or a mathematical function that defines the relative number of size-dependent particles. The PSD is one of the most common values offered by nanoparticle tracking analysis (NTA) system, along with mean and mode values. The particle size distribution shows the relative amounts of particles for each size. It offers the information regarding the particle distribution. The D-values or three-point specification of D10, D50, and D90 indicate the particle diameter at $10 \%, 50 \%$, and $90 \%$ of the cumulative distribution. Meanwhile, the span, an indication of the width of the distribution, is calculated as follows:

$$
\text { Span }=\frac{D 90-D 10}{D 50}
$$

In order to verify the feasibility of the E-CSID ImmunoSpheres for CTX isolation, we compared the results from five cancer patients' sample with those from three healthy donors' sample. After incubating both pre-separated plasma samples with the E-CSID ImmunoSpheres, we induced sphere degradation to retrieve the isolated CTXs, and the resulting solution was analyzed by NTA. The results are presented in Table $\mathrm{S} 1$. The mean values of exosome-seized particles were $305.1 \pm 67.1 \mathrm{~nm}$ and $161.2 \pm 48.0 \mathrm{~nm}(\mathrm{p}=0.028)$, respectively in cancer patients' samples $(n=5)$ and healthy donors' samples $(n=5)$. The PDS analysis also indicates that particles from the cancer patients are slightly bigger than those of health donors. Given that the level of background noise due to the decomposed hydrogel resides is equitable to both samples, it is worth noting that the difference in particle distribution is caused by dissimilarity between cancer patients' samples and healthy donors' samples. However, we should mention here about the limitation of NTA-based measurement in the research using hydrogel-based platform. Because NTA is based on size-based counting, the decomposed residues of hydrogel fibers may influence the final results. In addition, those residues were probably attached on the CTXs, so the measured size of the particles might be exaggerated, compared to their actual size.

Table S4. The Particle Size Distribution (PSD) of the Retrieved Samples from the E-CSID ImmunoSpheres

\begin{tabular}{|c|c|c|c|}
\hline & $\begin{array}{c}\text { Cancer Patients } \\
(\mathbf{n}=\mathbf{5})\end{array}$ & $\begin{array}{c}\text { Healthy Donors } \\
(\mathbf{n}=\mathbf{5})\end{array}$ \\
\hline \multicolumn{2}{|c|}{ Mean (nm) } & $305.10 \pm 67.1$ & $161.2 \pm 48.0$ \\
\hline \multicolumn{2}{|c|}{ Mode (nm) } & $189.80 \pm 96.5$ & $106.2 \pm 48.9$ \\
\hline \multirow{3}{*}{$\begin{array}{c}\text { Particle Size } \\
\text { Distribution } \\
\text { (PSD) }\end{array}$} & $\mathbf{D 1 0}(\mathbf{n m})$ & $113.50 \pm 34.9$ & $77.9 \pm 23.8$ \\
\cline { 2 - 4 } & $\mathbf{D 5 0}(\mathbf{n m})$ & $250.30 \pm 66.3$ & $155.6 \pm 23.4$ \\
\cline { 2 - 4 } & $\mathbf{D 9 0}(\mathbf{n m})$ & $573.40 \pm 111.6$ & $299.6 \pm 109.3$ \\
\hline
\end{tabular}




\section{S4-7. CTC/CTX Study: Patients Information and Result Summary}

The clinical information of the patients, enrolled for the present work, is described in Table S4.

Table S5. The Result and Analysis of the Circulating Markers Isolated by the Present CSID Hydrogel ImmunoSpheres

\begin{tabular}{|c|c|c|c|c|c|c|c|c|c|c|c|c|c|}
\hline \multirow{4}{*}{$\begin{array}{l}\text { Sample } \\
\text { ID }\end{array}$} & & & & & & \multicolumn{5}{|c|}{$\begin{array}{l}\text { Circulating Tumor Cells } \\
\text { (CTCs) }\end{array}$} & \multicolumn{2}{|c|}{$\begin{array}{l}\text { Circulating Tumor Exosome } \\
\text { (CTXs) }\end{array}$} & \multirow{4}{*}{ Note } \\
\hline & \multirow{2}{*}{\multicolumn{5}{|c|}{ Sample Description }} & \multicolumn{4}{|c|}{ Enumeration } & $\begin{array}{c}\text { Marker } \\
\text { Characterization }\end{array}$ & Enumeration & $\begin{array}{c}\text { Marker } \\
\text { Characterization }\end{array}$ & \\
\hline & & & & & & \multicolumn{4}{|c|}{ IF a) } & IF & NTA $^{\text {b) }}$ & IF & \\
\hline & Gender & Age & Stage & Location & Subtype & $\operatorname{EpCAM}(+)$ & $\mathrm{CK}(+)$ & $\operatorname{Dual}(+)$ & Total & EpCAM (+):(-) Ratio & Particles $/ \mathrm{mL}$ & E:M Ratio & \\
\hline $\mathrm{CC} 1$ & $\mathrm{~F}$ & 47 & 4 & $\begin{array}{c}\text { Descending } \\
\text { (left-sided) }\end{array}$ & $\begin{array}{c}\text { Adenocarci } \\
\text { noma } \\
\text { (M/D) }\end{array}$ & 4 & 0 & 4 & 4 & $100: 0$ & $190.85 \times 10^{6}$ & $62.19: 38.81$ & \\
\hline $\mathrm{CC} 2$ & M & 60 & 4 & $\begin{array}{c}\text { Sigmoid } \\
\text { (left-sided) }\end{array}$ & $\begin{array}{c}\text { Adenocarci } \\
\text { noma } \\
\text { (P/D) }\end{array}$ & 8 & 3 & 3 & 8 & $100: 38$ & $137.78 \times 10^{6}$ & $52.51: 47.49$ & \\
\hline $\mathrm{CC} 3$ & $\mathrm{~F}$ & 36 & 4 & $\begin{array}{l}\text { Ascending } \\
\text { (right-sided) }\end{array}$ & $\begin{array}{c}\text { Adenocarci } \\
\text { noma } \\
(\mathrm{M} / \mathrm{D})\end{array}$ & 17 & 13 & 12 & 18 & $100: 76$ & $16.64 \times 10^{6}$ & $48.42: 51.58$ & \\
\hline $\mathrm{CC} 4$ & M & 53 & 4 & $\begin{array}{l}\text { Ascending } \\
\text { (right-sided) }\end{array}$ & $\begin{array}{c}\text { Signet Ring } \\
\text { Cell } \\
\text { Carcinoma } \\
\end{array}$ & 9 & 9 & 7 & 11 & $100: 100$ & $17.15 \times 10^{6}$ & $49.32: 50.68$ & \\
\hline $\mathrm{CC} 5$ & M & 58 & 3 & $\begin{array}{c}\text { Sigmoid } \\
\text { (left-sided) }\end{array}$ & $\begin{array}{c}\text { Adenocarci } \\
\text { noma } \\
\text { (M/D) }\end{array}$ & 11 & 9 & 7 & 13 & $100: 82$ & $127.08 \times 10^{6}$ & $43.65: 56.35$ & \\
\hline
\end{tabular}




\section{S5. Summary}

\section{S5-1. Processing Time and Estimated Cost}

Lastly, we summarized the performance of the present liquid biopsy method using CSID immunospheres. Table S6 present the comparison table when considering $7.5 \mathrm{~mL}$ of whole blood processing. Because there is not enough information about commercial platform and other research group's tools, we supposed the mimicking operation for one batch reaction (immunomagnetic beads) and one flow reaction(microfluidics). We referred to the previously reported literatures to gathering information; but some conditions were highly varied according to the tools' characterization. (a) Processing time indicate the given time for reacting with the prepared sample, while total turnaround time includes pre-processing, post-processing, and retrieval procedure; the required time for immunostaining procedure and immunofluorescence imaging procedure are excluded here. The sample processing time of the present method is about 60 minutes, and total turnaround time is estimated to be 160 minutes. (b) estimated cost is the sum of the price per single run, including platform material (ferrofluids, PDMS, hydrogel), reagent for surface modification, antibodies, density gradient media (Ficoll ${ }^{\circledR}$ Paque), dilution buffer, washing buffer, and so on; the price for immunostaining dye and equipment use fee are excluded here. The cost reduction was approachable extremely affordable platform material (alginate and PVA) and the minimized the antibody usage (most expensive element of the affinity-based platform). The estimated cost is 8.4 12.6 USD (total 7 C-CSID ImmunoSpheres) and 9.1 14.7 USD (total 7 E-CSID ImmunoSpheres). When CTC study and CTX study are conducted together ("dual profiling"), the total estimated cost is 18.2 27.3 USD (per 7.5 mL whole blood). This means that simultaneous analysis of CTC and CTX is available with a comparable cost to the immunomagnetic bead-based method (14.5 37.3 USD per batch). When considering the present method does not precisely require $7.5 \mathrm{~mL}$ of sample volume, this cost estimation could be reduced more, and it is possible to reach unmatchable affordability.

Table S6. The Estimation of Time, Cost, and Resources

\begin{tabular}{|c|c|c|c|c|c|c|c|c|c|c|}
\hline \multirow[b]{2}{*}{ Type } & \multirow[b]{2}{*}{ Description } & \multicolumn{2}{|c|}{$\begin{array}{c}\text { Sample } \\
\text { Preparation }\end{array}$} & \multicolumn{3}{|c|}{ Resources } & \multicolumn{2}{|c|}{ Processing Time (min) } & \multirow{2}{*}{$\begin{array}{c}\text { Estimated } \\
\text { Cost } \\
\text { (USD) }^{* * *}\end{array}$} & \multirow[b]{2}{*}{ Note } \\
\hline & & $\begin{array}{l}\text { Whole } \\
\text { Blood }\end{array}$ & $\begin{array}{l}\text { Desnty- } \\
\text { gradient } \\
\text { Media* }\end{array}$ & $\begin{array}{c}\text { Platform } \\
\text { Unit } \\
\text { (Material) }\end{array}$ & $\begin{array}{c}\text { Surface } \\
\text { Area }\left(\mathrm{mm}^{2}\right)\end{array}$ & $\begin{array}{l}\text { Antibody } \\
\text { (ug) }\end{array}$ & $\begin{array}{c}\text { Sample } \\
\text { Processing } \\
\text { Time (min) }\end{array}$ & $\begin{array}{c}\text { Total } \\
\text { Turnaround } \\
\text { Time (min) }\end{array}$ & & \\
\hline Batch & $\begin{array}{l}\text { Immuno- } \\
\text { magnetic } \\
\text { Beads }\end{array}$ & 7.5 & Yes/No & $\begin{array}{c}1 \text { Batch } \\
\text { (Magnetic } \\
\text { beads) }\end{array}$ & N/A & $1 \sim 10$ & $\sim 60$ & $140 \sim 170$ & $14.5 \sim 37.3$ & $\begin{array}{l}\text { CTC- } \\
\text { only }\end{array}$ \\
\hline Flow & $\begin{array}{l}\text { Micro- } \\
\text { fluidics }\end{array}$ & 7.5 & Yes/No & $\begin{array}{l}1 \text { Chip } \\
\text { (PDMS) }\end{array}$ & $400 \sim 970$ & $1 \sim 20$ & $60 \sim 240$ & $150 \sim 420$ & $12.6 \sim 33.8$ & $\begin{array}{l}\text { CTC- } \\
\text { only }\end{array}$ \\
\hline \multirow{3}{*}{ Batch } & $\begin{array}{l}\text { C-CSID } \\
\text { Immuno- } \\
\text { Spheres } \\
\end{array}$ & \multirow{2}{*}{7.5} & \multirow{2}{*}{ Yes } & $\begin{array}{l}7 \text { spheres } \\
\text { /7 wells } \\
\text { (hydrogel) } \\
\end{array}$ & $\begin{array}{c}>128 \\
(\sim 18.3 \times 7) \\
\end{array}$ & $\begin{array}{c}0.07 \\
(0.01 \times 7)\end{array}$ & 60 & 160 & $\begin{array}{c}8.4 \sim 12.6 \\
(1.2 \sim 1.8 \times 7)\end{array}$ & CTC \\
\hline & $\begin{array}{l}\text { E-CSID } \\
\text { Immuno- } \\
\text { Spheres }\end{array}$ & & & $\begin{array}{l}7 \text { spheres } \\
/ 7 \text { wells } \\
\text { (hydrogel) } \\
\end{array}$ & $\begin{array}{c}>128 \\
(\sim 18.3 \times 7)\end{array}$ & $\begin{array}{c}0.7 \\
(0.1 \times 7)\end{array}$ & 60 & 160 & $\begin{array}{c}9.1 \sim 14.7 \\
(1.3 \sim 2.1 \times 7)\end{array}$ & CTX \\
\hline & $\begin{array}{c}\text { Dual } \\
\text { Profiling } \\
\text { (C-CSID+ } \\
\text { E-CSID) }\end{array}$ & 7.5 & Yes & $\begin{array}{c}7+7 \text { spheres } \\
\text { /7+7 wells } \\
\text { (hydrogel) }\end{array}$ & $\begin{array}{c}>128 \\
(\sim 18.3 \times 7)\end{array}$ & $\begin{array}{c}0.77 \\
(0.11 \times 7)\end{array}$ & 60 & 160 & $\begin{array}{c}18.2 \sim 27.3 \\
(2.6 \sim 3.9 \times 7)\end{array}$ & $\begin{array}{l}\text { CTC+ } \\
\text { CTX }\end{array}$ \\
\hline
\end{tabular}




\section{S6. Reference}

(1) Chan, E.-S.; Lee, B.-B.; Ravindra, P.; Poncelet, D. Prediction Models for Shape and Size of Ca-Alginate Macrobeads Produced through Extrusion-Dripping Method. Journal of Colloid and Interface Science 2009, 10.

(2) Kostov, G.; Angelov, M.; Mihaylov, I.; Poncelet, D. Mechanical Properties of Ca-Alginate Beads for Ethanol Fermentation with Immobilized Yeast. Revue de génie industriel 2010, 11.

(3) Sawada, T.; Araki, J.; Yamashita, T.; Masubuchi, M.; Chiyoda, T.; Yunokawa, M.; Hoshi, K.; Tao, S.; Yamamura, S.; Yatsushiro, S.; Abe, K.; Kataoka, M.; Shimoyama, T.; Maeda, Y.; Kuroi, K.; Tamura, K.; Sawazumi, T.; Minami, H.; Suda, Y.; Koizumi, F. Prognostic Impact of Circulating Tumor Cell Detected Using a Novel Fluidic Cell Microarray Chip System in Patients with Breast Cancer. EBioMedicine 2016, 11, 173-182. https://doi.org/10.1016/j.ebiom.2016.07.027.

(4) Allard, W. J.; Matera, J.; Miller, M. C.; Repollet, M.; Connelly, M. C.; Rao, C.; Tibbe, A. G. J.; Uhr, J. W. Tumor Cells Circulate in the Peripheral Blood of All Major Carcinomas but Not in Healthy Subjects or Patients With Nonmalignant Diseases. Clinical Cancer Research 2004, 10 (20), 9.

(5) Talasaz, A. H.; Powell, A. A.; Huber, D. E.; Berbee, J. G.; Roh, K.-H.; Yu, W.; Xiao, W.; Davis, M. M.; Pease, R. F.; Mindrinos, M. N.; Jeffrey, S. S.; Davis, R. W. Isolating Highly Enriched Populations of Circulating Epithelial Cells and Other Rare Cells from Blood Using a Magnetic Sweeper Device. Proceedings of the National Academy of Sciences 2009, 106 (10), 3970-3975. https://doi.org/10.1073/pnas.0813188106.

(6) Nagrath, S.; Sequist, L. V.; Maheswaran, S.; Bell, D. W.; Irimia, D.; Ulkus, L.; Smith, M. R.; Kwak, E. L.; Digumarthy, S.; Muzikansky, A.; Ryan, P.; Balis, U. J.; Tompkins, R. G.; Haber, D. A.; Toner, M. Isolation of Rare Circulating Tumour Cells in Cancer Patients by Microchip Technology. Nature 2007, 450 (7173), 1235-1239. https://doi.org/10.1038/nature06385.

(7) Stott, S. L.; Hsu, C.-H.; Tsukrov, D. I.; Yu, M.; Miyamoto, D. T.; Waltman, B. A.; Rothenberg, S. M.; Shah, A. M.; Smas, M. E.; Korir, G. K.; Floyd, F. P.; Gilman, A. J.; Lord, J. B.; Winokur, D.; Springer, S.; Irimia, D.; Nagrath, S.; Sequist, L. V.; Lee, R. J.; Isselbacher, K. J.; Maheswaran, S.; Haber, D. A.; Toner, M. Isolation of Circulating Tumor Cells Using a Microvortex-Generating Herringbone-Chip. Proceedings of the National Academy of Sciences 2010, 107 (43), 18392-18397. https://doi.org/10.1073/pnas.1012539107.

(8) Hong, B.; Zu, Y. Detecting Circulating Tumor Cells: Current Challenges and New Trends. Theranostics 2013, 3 (6), 377-394. https://doi.org/10.7150/thno.5195.

(9) Hillig, T.; Horn, P.; Nygaard, A.-B.; Haugaard, A. S.; Nejlund, S.; Brandslund, I.; Sölétormos, G. In Vitro Detection of Circulating Tumor Cells Compared by the CytoTrack and CellSearch Methods. Tumor Biol. 2015, 36 (6), 4597-4601. https://doi.org/10.1007/s13277-015-3105-z.

(10) Gleghorn, J. P.; Pratt, E. D.; Denning, D.; Liu, H.; Bander, N. H.; Tagawa, S. T.; Nanus, D. M.; Giannakakou, P. A.; Kirby, B. J. Capture of Circulating Tumor Cells from Whole Blood of Prostate Cancer Patients Using Geometrically Enhanced Differential Immunocapture (GEDI) and a Prostate-Specific Antibody. Lab Chip 2010, 10 (1), 27-29. https://doi.org/10.1039/B917959C.

(11) Li, P.; Gao, Y.; Pappas, D. Negative Enrichment of Target Cells by Microfluidic Affinity Chromatography. Anal. Chem. 2011, 83 (20), $7863-$ 7869. https://doi.org/10.1021/ac201752s.

(12) Hyun, K.-A.; Lee, T. Y.; Jung, H.-I. Negative Enrichment of Circulating Tumor Cells Using a Geometrically Activated Surface Interaction Chip. Anal. Chem. 2013, 85 (9), 4439-4445. https://doi.org/10.1021/ac3037766.

(13) Bu, J.; Kang, Y.-T.; Kim, Y. J.; Cho, Y.-H.; Chang, H. J.; Kim, H.; Moon, B.-I.; Kim, H. G. Dual-Patterned Immunofiltration (DIF) Device for the Rapid Efficient Negative Selection of Heterogeneous Circulating Tumor Cells. Lab Chip 2016, 16 (24), 4759-4769. https://doi.org/10.1039/C6LC01179A.

(14) Kim, Y. J. Combination of Negative and Positive Microfluidic Immunofiltration for the Selective Enrichment of Circulating Tumor Cells and Exosomes. Ph.D. Dissertation, Korea Advanced Institute of Science and Technology, 2017.

(15) Théry, C.; Zitvogel, L.; Amigorena, S. Exosomes: Composition, Biogenesis and Function. Nat Rev Immunol 2002, 2 (8), 569-579. https://doi.org/10.1038/nri855.

(16) Marzesco, A.-M. Release of Extracellular Membrane Particles Carrying the Stem Cell Marker Prominin-1 (CD133) from Neural Progenitors and Other Epithelial Cells. Journal of Cell Science 2005, 118 (13), 2849-2858. https://doi.org/10.1242/jcs.02439.

(17) Chiu, Y.-J.; Cai, W.; Shih, Y.-R. V.; Lian, I.; Lo, Y.-H. A Single-Cell Assay for Time Lapse Studies of Exosome Secretion and Cell Behaviors. Small 2016, 12 (27), 3658-3666. https://doi.org/10.1002/smll.201600725. 